\title{
DIA A DE UM ENGENHEIRO DE PRODUÇÃO DENTRO DA EMPRESA
}

\author{
Vitor Pereira Araújo-vitorpereiraaraujooo@gmail.com \\ Caio Romanhol - caioromanhol2@gmail.com \\ ArthurRodrigues Benete -arthur.benete@alunos.unis.edu.br \\ Yago Pereira Barizon-yagobarizon20@hotmail.com \\ Tiago Nazaré- tiago.nazare@professor.unis.edu.br
}

\section{RESUMO}

A necessidade de formação de profissionais ligados à área de Engenharia de Produção, tem se tornado cada vez mais latente no mercado, isto porque às instituições têm buscado cada vez mais qualidade em seus processos, como forma de vencer a competição. A partir daí a atuação da Engenharia de Produção passou a ser cada vez mais necessária, especialmente na busca da produtividade e qualidade que passaram a serem pressupostos básicos para o sucesso de uma instituição. Da mesma forma houve consequências sobre a atuação do profissional desta área que teve que se tornar mais dinâmico e se habilitar nas várias técnicas e princípios da Engenharia de Produção, para que assim pudesse contribuir para os sucessos da empresa no mundo globalizado e competitivo.O propósito é demonstrar a vida de um engenheiro dentro do seu local de trabalho, no qual ele atua na área de engenharia de produção, com isso contribuindo para futuros engenheiros. Foi enviado um questionário a engenheiros de produção atuantes, onde foram analisadas as respostas obtidas o resultado foi que existe um leque muito grande para os engenheiros determinarem qual área trabalhar, mas não existem muitas vagas ofertadas no mercado de trabalho.

Palavras- chave:Engenharia, Produção, Mercado. 


\section{1- INTRODUÇÃO}

O empreendedorismo e a inovação ganharam maior notoriedade em nossos dias, sobretudo em razão da reestruturação produtiva centrada em mudanças tecnológicas e organizacionais com reflexos no mercado de trabalho, evidenciado pelo declínio do emprego.

À medida que a competitividade se intensifica e amplia-se para além das fronteiras nacionais, intensifica-se e amplia-se também a relevância e a abrangência da atuação dos engenheiros que, por definição, são os responsáveis pelo desenvolvimento técnico científico das organizações e, mais amplamente, da nação.

Jardim (2017, s./p.) ao dizer que "a Engenharia de Produção deve ser percebida, então, por sua abrangência intrínseca, que traz para a formação básica do engenheiro outras áreas do saber como, por exemplo, Finanças, Economia, Administração, Psicologia, Ciências Contábeis e Jurídicas", por isto trazendo grandes contribuições para a empresa.

Neste contexto, é de se esperar que as empresas estimulem seus engenheiros a empreender e que estes estejam dispostos a assumir responsabilidades e determinados para acabar projetos e sejam ainda criativos e tolerantes aos riscos intrínsecos desse processo. A geração de valores adicionais de competitividade dentro das organizações geralmente significa soluções inovadoras.

Sonia (2020) considera que o dia a dia do engenheiro de produção contém muitos processos administrativos, mas também envolve relacionamento direto com as pessoas. Além disso, é comum que haja bastante planejamento, cálculos e estudos de estatísticas e variáveis. Ou seja, o engenheiro de produção pode desempenhar diversos papéis em um negócio, em diferentes setores, mas sempre com o objetivo de tornar os processos mais vantajosos para o dia a dia da organização. 
No empreendedorismo e na Engenharia, mais importante do que saber fazer é criar o que fazer, é conhecer a cadeia econômica, o ciclo produtivo, entender do negócio, saber transformar necessidades em especificações técnicas, transformar conhecimento em riqueza.

A competitividade global e o cenário brasileiro de mudanças no processo produtivo industrial e nas relações de trabalho apontam a demanda pelo perfil empreendedor do Engenheiro de Produção. Mas o desenvolvimento e a qualificação deste perfil têm caracterizado um padrão ainda sem resposta na maior parte das empresas, nos engenheiros, nas instituições de ensino e pesquisa.

O objetivo deste trabalho é colaborar para as discussões com relação ao perfil do engenheiro no setor de empreendedorismo, ou seja, trabalho autônomo e dos engenheiros que atuam em empresas na área de engenharia de produção. Foi enviado um questionário para engenheiros que trabalham na área. $O$ engenheiro aqui estudado é aquele que desempenha suas atividades profissionais na produção industrial.

\section{2- Referencial Teórico}

\subsection{Profissional}

Almeida (et al., 2016) considera que o profissional da Engenharia de Produção envolve-se com todos os problemas que ocorrem dentro da automação de processos, até o desenvolvimento de tecnologias e questões ambientais na empresa, atentando ainda para fatores energéticos e administrativos. Assim, quanto mais o mercado se abre, maior é a demanda das indústrias por técnicas e tecnologias de fabricação, que façam os produtos mais competitivos e de qualidade, pois somente assim elas conseguirão manter-se no mercado e é nesse momento que o engenheiro de produção apresenta sua formação e seus conhecimentos para contribuir com a instituição.

$O$ engenheiro de produção pode atuar em processos específicos da empresa, como logística ou controle de qualidade, ou então ser responsável pela gestão global de todos os processos produtivos. Como maior responsável pelo sistema produtivo de uma empresa, ele planeja fluxos de produção, 
implementa ações de melhoria para redução de estoques e aplica estratégias de otimização dos sistemas de abastecimento (UNISC 2020).

Atualmente, percebe-se a necessidade de engenheiros de produção com perfis diferentes dos formados nas duas últimas décadas. Além do conhecimento técnico, é necessário que os profissionais da área possuam habilidades e capacidade de análise crítica sobre os projetos e situações que envolvam qualquer tipo de empresa (CARMO; BARROSO; ALBERTIN, 2010).

Sonia (2020) considera que o dia a dia do engenheiro de produção contém muitos processos administrativos, mas também envolve relacionamento direto com as pessoas. Além disso, é comum que haja bastante planejamento, cálculos e estudos de estatísticas e variáveis. Ou seja, o engenheiro de produção pode desempenhar diversos papéis em um negócio, em diferentes setores, mas sempre com o objetivo de tornar os processos mais vantajosos para o dia a dia da organização.

\subsection{Gestão de Produção, Projetos e Financeiros}

Costa (2017) consideram que a gestão da produção tem um caráter essencialmente proativo, atuando tanto em preocupações tradicionais que buscam trazer a eficiência do processo e redução de custos, possibilitando assim que haja maior satisfação da clientela com a qualidade do produto, o cumprimento de prazos, adaptação às mudanças realizadas no mercado, desenvolvimento de novos produtos, entre outros aspectos.

Azevedo e Rosa (2003) consideram que é a multidisciplinaridade que está contida no processo de formação do engenheiro de produção que faz com que ele possa atuar em diversas áreas de uma empresa, desde a gestão de projetos, aos sistemas produtivos, possibilitando que a instituição racionalize a utilização dos recursos e melhore seu desempenho de forma global.

Para elucidar problemas de produção e organizacionais, os engenheiros industriais estudam os produtos e suas demandas. Desenvolvem sistemas de controle gerencial para auxiliar no controle de custos e gestão financeira, além de projetar sistemas de planejamento e controle da produção (PARREIRAS PEDRO, 2021). 


\subsection{Tecnologia e Automatização}

Por um lado, a tecnologia tem ocupado crescente espaço e destaque nos processos industriais e a automatização representa um impulsionador de resultados, por meio de softwares ou sistemas produtivos automatizados, que geram resultados positivos para as empresas (PINTO; NUNES; VIERO, 2016).

\subsection{Habilidades e Competências}

Para Katz (apud STONER, 1999) uma habilidade é a capacidade de transformar conhecimento em ação e que resulta em um desempenho desejado. Katz separa as habilidades em três: técnicas, humanas e conceituais.

Segundo Chiavenato $(2014$, p. 3) a habilidade técnica "consiste em utilizar conhecimentos, métodos, técnicas e equipamentos necessários para o desempenho de tarefas específicas, por meio da experiência e educação". A habilidade humana "consiste na capacidade e facilidade para trabalhar com pessoas, comunicar, compreender suas atitudes e motivações e liderar grupos de pessoas". Já a habilidade conceitual é a: Capacidade de compreender a complexidade da organização com um todo e o ajustamento do comportamento de suas partes. Essa habilidade permite que a pessoa se comporte de acordo com os objetivos da organização como um todo e não apenas de acordo com os objetivos e as necessidades de seu departamento ou grupo imediato.

Para Perrenoud (1999, p. 7), competência é a "capacidade de agir eficazmente em um determinado tipo de situação, apoiada em conhecimentos, mas sem limitar-se a eles", enquanto habilidade, pode ser entendida como uma sequência de modos operatórios e uma série de procedimentos mentais que o indivíduo aciona para resolver uma situação.

Green (2002) defende que existem duas dimensões de competências: as organizacionais e as individuais. Segundo o autor, as competências organizacionais - também chamadas de competências essenciais - são conjuntos únicos de conhecimentos técnicos e habilidades que possuem ferramentas que causam impacto em produtos e serviços múltiplos em organizações, fornecendo desta forma uma vantagem competitiva no mercado. 


\section{3- METODOLOGIA}

A elaboração do artigo definida por meio da análise sobre engenharia de produção sendo funcionário da empresa ou prestando serviços como autônomo, atuando em sua formação. Pesquisas sobre o tema foram realizadas e seus conceitos apresentados. $O$ presente estudo feito em artigos científicos e informações obtidas de entrevistas com engenheiros consagrados na área. Portanto a metodologia consistiu no levantamento e coleta dos dados para o estudo, que teve início com o pedido de permissão feito por meio de contatos por e-mail e por telefone para a autorização dos engenheiros. Após a permissão concedida por um engenheiro de produção da empresa Guarani Plast (Guarani Plast S.A., Miraí, Mg., Brasil)e um engenheiro de produção autônomo, foram feitas conversas via WhatsApp, perguntas foram enviadas com 1 meses de antecedência da conclusão do artigo, que estão em apêndice conforme elaborada pelo autor.

\section{Questionário enviado:}

- $\quad$ O que você faz na área de engenharia de produção?

- Como está o mercado para os engenheiros de produção?

- Atua como empregado ou você possui uma empresa na área?

- Qual a dificuldade em ser um engenheiro de produção?

- $\quad$ O que você está fazendo para se manter atualizado com a tecnologia mais recente?

- Onde você gostaria de estar com sua carreira daqui a cinco anos?

- Porque escolheu trabalhar na área de engenharia?

- Como um engenheiro pode se destacar em seu trabalho ou empresa?

Foi utilizado Amostra Aleatória Simples, com um prazo de um mês para resposta dos participantes.

Segundo Antunes (2011), amostra aleatória simples é um subconjunto de indivíduos (a amostra) selecionado totalmente ao acaso a partir de um 
conjunto maior (a população) por um processo que garanta que: Todos os indivíduos da população têm a mesma probabilidade de ser escolhidos para a amostra, e

cada subconjunto possível de indivíduos (amostra) tem a mesma probabilidade de ser escolhido que qualquer outro subconjunto de indivíduos.

Foram escolhidos somente dois engenheiros, devido à falta de experiência na área da engenharia e pouco tempo de estudo.

\section{4- RESULTADOS E DISCUSSÕES}

Os resultados que foram obtidos com a pesquisa, foram feitos através de engenheiros de produção, formados e atuantes na área.

"Atuo na área de programação da produção, fazendo um link entre o comercial da empresa e a produção, garantido que todos os pedidos passados pelos clientes serão fabricados dentro do prazo acordado. Controle dos insumos de produção, afim de garantir que não haja faltas, sempre mantendo um nível mínimo de cada insumo de acordo com média de consumo. Controle de eficiência fabril e perdas oriundas do processo."

"A escolha desta área, foi pensando que existe um leque muito grande de atuação dentro do mercado de trabalho, podendo se relacionar e agregar em muitas áreas diferentes."

"Atualmente a maior dificuldade em ser um engenheiro de produção são as poucas vagas ofertadas no mercado de trabalho, tanto pelo cenário provocado pela corona vírus, quanto pelo cenário interno do país. Como há muitos formados na área e pouca oferta de vagas, acaba-se que por muitas das vezes é preciso trabalhar como analistas para adquirir maior conhecimento de chão de fábrica após a formação."

"Foi cadastrado meu e-mail nos principais meios de comunicação do país exame, isto é, G1, R7 qualquer novidade, oscilação de mercado estou sempre ciente. Uso muito também o LinkedIn, pois nele estou sempre ligado em novidades, buscas e tendências de mercado, fora os cursos relacionados a minha área." 
"Devido à crise que se encontra em nível mundial, o mercado deu uma desacelerada, há muitos engenheiros de produção desempregados. No momento a mais demanda de busca de empregos do que vagas."

“Um engenheiro que tenha humildade para com a sua profissão sabe que sempre vai estar aprendendo e buscando realizar um serviço melhor que o outro, tornando-se um ótimo profissional."

O engenheiro de produção pode atuar na indústria, setor de serviços, mercado financeiro e até no meio educacional. Atualmente, os profissionais da área estão habilitados a atuar em diversos setores industriais, da construção civil até a gestão hospitalar. Além disso, gerenciam recursos humanos, financeiros e materiais de uma empresa, a fim de elevar sua produtividade e rentabilidade das esferas mercadológicas.

Todas essas características formam um profissional cada vez menos técnico e mais multifacetado, perfil demandado pelo mercado de trabalho. Para tanto, as vivências práticas são cobradas desde a graduação, já que a área é majoritariamente prática.

Foi aplicado um questionário para engenheiros de produção, com 0 objetivo de avaliar a atuação do engenheiro de produção no mercado de trabalho.

A primeira questão, trata-se de qual área estão atuando dentro de sua formação, e de acordo com o mesmo, age na área de programação de produção, onde faz um link entre o comercio e a produção.

\begin{abstract}
JARDIM E COSTA (2017) consideram que a gestão da produção tem um caráter essencialmente proativo, atuando tanto em preocupações tradicionais que buscam trazer a eficiência do processo e redução de custos, possibilitando assim que haja maior satisfação da clientela com a qualidade do produto, o cumprimento de prazos, adaptação às mudanças realizadas no mercado, desenvolvimento de novos produtos, entre outros aspectos.
\end{abstract}

$\mathrm{Na}$ segunda questão foi abordado como está o mercado para os engenheiros de produção, e a resposta obtida, foi a seguinte: "Diante da crise que se encontra no cenário mundial, o mercado deu uma desacelerada e que no momento há mais demanda do que vagas." 
Na terceira questão foi perguntado se atuam como empregado ou possuí alguma empresa atuante na área. A resposta obtida foi que trabalhano setor privado como empregado.

$\mathrm{Na}$ quarta questão, foi qual a dificuldade de ser um engenheiro de produção. Um dos maiores desafios para um engenheiro de produção está na economia do País, que não está passando por um bom momento. Com a pandemia e as constantes notícias de desemprego, muitas pessoas estão perdendo suas principais fontes de renda. As vagas que estão disponíveis, com os cortes, foram reduzidas, e a quantidade de profissionais no mercado é cada vez maior, acaba que por muita das vezes, após a formação, ter que trabalhar como analistas para adquirir um maior conhecimento de chão de fábrica.

A quinta questão foi perguntado sobre como o entrevistado faz para se manter atualizado com a tecnologia mais recente e as tendências do mercado. A resposta foi que possui cadastros em sites de meios de comunicação do país, que sempre estão atualizando sobre as novidades, oscilações do mercado entre outras questões.

Um importante requisito que as empresas esperam hoje em dia é um bom rendimento de seus funcionários. Assim, investir em aperfeiçoamento contínuo é um fator fundamental para o aumento de sua produtividade e uma decorrente valorização na empresa.

$\mathrm{Na}$ sexta pergunta, foi questionado o porquê escolheu a área de engenharia de produção. O retorno foi que a área de engenharia de produção, tem um leque bastante amplo de atuação dentro do mercado de trabalho, podendo se relacionar e agregar em muitas áreas diferentes.

Já a sétima pergunta foi como um engenheiro de produção pode se destacar no trabalho.

A primeira dica de como ser um bom engenheiro de produção é investir no aprimoramento da sua oratória.

Aprender com quem é mais experiente na profissão é outra maneira de como ser um bom engenheiro de produção.

Faça cursos de atualização ou para aprender novas ferramentas que você precisa dominar no seu trabalho atual. 
Ter uma postura aberta permite ampliar seu ponto de vista e ganhar novas perspectivas. Além disso, contribui para criar uma cultura organizacional positiva.

Os cursos e treinamentos organizacionais vão ajudá-lo a evoluir e superar os desafios da profissão.

Não se prenda a velhos, conceitos, ideias e funções. Analise com atenção para entender os motivos e trace suas estratégias para se adaptar de forma positiva.

Ser o profissional que você deseja depende muito da dedicação que você irá investir. Ter um caminho a seguir vai ajudá-lo a pensar no futuro.

\section{5- CONCLUSÃO}

Atualmente a maior dificuldade em ser um engenheiro de produção são as poucas vagas ofertadas no mercado de trabalho, tanto pelo cenário provocado pela pandemia atual, quanto pelo cenário interno do país. Devido à crise que se encontra em nível mundial, o mercado deu uma desacelerada, há muitos engenheiros de produção desempregados. No momento a mais demanda de busca de empregos do que vagas.

Portanto foram buscadospensamentos diferentes no mercado de trabalho, direcionando a perspectiva de um engenheiro de produção, e como sobreviver no meio de trabalho diante a uma pandemia, conseguindo conquistar seus objetivos.Foi feito um questionário para profissionais da área para compreender os problemas que existem no mercado, os conselhos obtidos nas respostas foram, se manter atualizados nos principais meios de comunicação do país, estando sempre por dentro de qualquer novidade e fazendo cursos específicos que agregam no seu dia a dia.

Conclui -se que o engenheiro de produção deve ser uma ponte que liga os conceitos de responsabilidade social e a sustentabilidade para a pratica diária nas empresas,sendo o principal agente dessa participação das organizações na sociedade, pois éde sua competência o atendimento as demandas da sociedade, levando emconsideração aspectos humanos, econômicos, sociais e ambientais. 


\section{6- REFERÊNCIA BIBLIOGRÁFICA}

ALMEIDA, F. C. de et al. Áreas de atuação e conhecimento do engenheiro de produção frente ao mercado de trabalho do Sul Fluminense. Não paginado. Disponível em: <http://www.aedb.br/seget/arquivos/artigos.pdf>. Acesso em: 24 maio. 2021.

ANTUNES,R.Amostragem aleatória simples. 2011. Disponível em: $<$ https://sondagenseestudosdeopiniao.wordpress.com/amostragem/amostrasprobabilisticas-e-nao-probabilisticas/amostragem-aleatoria-simples/>. Acesso em: 20 maio. 2021.

AZEVEDO, D. L.; ROSA, L. C; COSTA, L. C. A necessidade e atuação do profissional da engenharia de produção na indústria local. Rio Verde, UNIRV, 2017. Disponível em:

$<$ https://www.unirv.edu.br/conteudos/fckfiles/files/A\%20NECESSIDADE\%20E\% 20ATUA\%c3\%87\%c3\%830\%20DO\%20PROFISSIONAL\%20DA\%20ENGENH ARIA\%20DE $\% 20$ PRODU\%c3\%87\%c3\%830\%20NAS\%20IND\%c3\%9aSTRIAS \%20LOCAL.pdf>. Acesso em: 25 de maio. De 2021.

Engenharia de produção: O que faz? Santa Cruz do Sul, EAD UNISC, 2019. Disponível em: <https://ead.unisc.br/blog/engenharia-de-producao>. Acesso em: 25 de maio. De 2021.

JARDIM, E. G. M.; COSTA, R. S. O papel do engenheiro de produção. Não paginado. Disponível em:

$<$ http://www.tgps.com.br/site old/jornal01/Artigo01.pdf>. Acesso em: 20 maio 2021.

PARREIRAS, Pedro. A importância do profissional da engenharia de produção em uma indústria. Rio de Janeiro, Uni Redentor Centro Universitário, 2016. Disponível em: <https://www.nomus.com.br/blogindustrial/a-importancia-do-profissional-da-engenharia-de-producao-em-umaindustria/>. Acesso em: 25 de maio. De 2021.

PARREIRAS, Pedro. Descubra qual o futuro do profissional de engenharia de produção. Rio de Janeiro: Nomus blog industrial, 2020. Disponível em: $<$ https://www.nomus.com.br/blog-industrial/descubra-qual-o-futuro-profissionalde-engenharia-deproducao/\#: :text=Avan $\%$ C3\%A7os $\% 20$ e $\% 20$ novas $\% 20$ tecnologias $\% 20 \%$ E2\% 80\%93\%20Engenharia\%20de\%20produ\%C3\%A7\%C3\%A30\%20em\%202030\& text=Internet\%20das\%20coisas\%20> . Acesso em: 25 de maio. De 2021. 
PAZ, Walquíria; SILVA, Mônica; MORAES, Camila. Proposta de melhoria utilizando engenharia de métodos. Belo Horizonte, Revista Cientifica Multidisciplinar Núcleo do Conhecimento, 2021. Disponível em:

$<$ https://www.nucleodoconhecimento.com.br/engenharia-de-

producao/utilizando-engenharia?pdf=80325>. Acesso em: 25 de maio. De 2021.

PINTO, J. R. C.; NUNES, F. L.; VIERO, C. F. Avaliação dos Ganhos de Produtividade e Redução de Custos Gerados pela Automação de Processo em uma Empresa Calçadista: um estudo de caso. Revista Espacios, v. 36, n. 16, p. 6, 2015. Disponível em: <http://www.revistaespacios.com/a15v36n16/15361606.html>. Acesso em: 20 maio. 2021.

REGINA, Sonia. Engenharia de produção: O que faz e formação do engenheiro. Disponível em: <https://ead.univali.br/blog/engenharia-deproducao-o-que-faz>. Acesso em: 19 maio. 2021.

SILVA, Mariana; ABREU, Bryan; OLIVEIRA, César. Características empreendedoras do discente do curso de engenharia de produção na indústria 4.0. Fortaleza: Revista Gestão e Analise, 2019. Disponível em: $<$ https://periodicos.unichristus.edu.br/gestao/article/view/2046/854>. Acesso em: 25 de maio. De 2021.

STONER, J. A. F.; FREEMAN, R. E.; CHIAVENATO; PERRENOUD, P; GREEN, P. C. Competências e habilidades gerenciais de um engenheiro de produção sob a perspectiva das organizações. São Paulo, VIIISingep, 2020. Disponível em:

$<$ http://submissao.singep.org.br/8singep/arquivos/485.pdf>. Acesso em: $25 \mathrm{de}$ maio. De 2021.

TADEU, Alexandre. Uma avaliação sobre as competências e habilidades do engenheiro de produção no ambiente industrial. São Paulo: Gestão e Produção, 2018. Disponível em: <https://www.scielo.br/pdf/gp/v25n2/0104530X-gp-0104-530X2081-18.pdf>. Acesso em: 25 de maio. De 2021. 
